\title{
EXPERIMENTAL DATA ON EPOXY RESIN SAMPLES: SMALL PARTIAL DISCHARGES AT INCEPTION VOLTAGE AND SOME THOUGHTS ON THE POSSIBILITY OF THE EXISTENCE OF CHARGING PHENOMENA BELOW INCEPTION VOLTAGE
}

\author{
Michael G. DANIKAS ${ }^{*}$ - Xu ZHAO ${ }^{* *}$ - Yong-hong CHENG ${ }^{* *}$
}

\begin{abstract}
In this paper, some results are presented on experiments concerning partial discharges (PD) behavior of epoxy resin samples. The main idea is to see whether a sample with PD at its inception voltage, still presents some tendency to charging effects below inception. An effort is being made to relate the present work with previous publications on the same main idea. The experiment arrangement is three layers of epoxy resin with a void in middle layer. Different level voltages under inception voltage are applied to the arrangement and different PD waves are registered under different level voltages. To make sure that the tendency to charging effects below inception, infrared spectrum analysis is also conducted and the result is content to clarify our objective.
\end{abstract}

K e y w or d s: partial discharges, below inception voltage, epoxy resin

\section{INTRODUCTION}

Although a great number of people did research on partial discharges (PD), their mechanisms, the parameters that influence them and their effect on insulating materials, relatively little is known on the possible effects of charging phenomena below the inception voltage. Events which may occur below the so-called inception voltage have been the subject of published work $[1,2]$. In those papers, polyethylene samples were used which had a void. The important aspect of these papers was that pointed electrodes were used touching the opposite void surface in order to simulate local inhomogeneities on the surface of the voids. Such papers indicated that there were some phenomena below the inception voltage which caused similar degradation by-products as the inception voltage or even voltages below it [1]. In the context of the present work, we investigate the possibility of the existence of such phenomena with a different electrode arrangement and a different insulating material. The material used was epoxy resin and the electrode arrangement was different from that of $[1,2]$.

\section{EXPERIMENTAL ARRANGEMENT}

Figure 1 is the diagram of the experiment setup. Detecting impendence is $\mathrm{RC}$ circuit, in which the value of $\mathrm{R} 1$ and $\mathrm{R} 2$ is $2000 \Omega$ and $200 \Omega$ respectively, and the value of $\mathrm{C}$ is $1500 \mathrm{pF}$. The value of $\mathrm{R} 3$, protecting the measuring device, is $1000 \Omega$. The oscilloscope (Tektronix TDS3052C, $500 \mathrm{MHz}, 5 \mathrm{GS} / \mathrm{s}$ ) is used to measure the waveform of $\mathrm{PD}$ happening at and below the inception voltage.

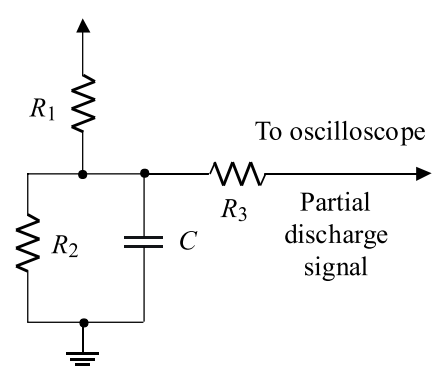

Fig. 1. Detecting circuit for partial discharges

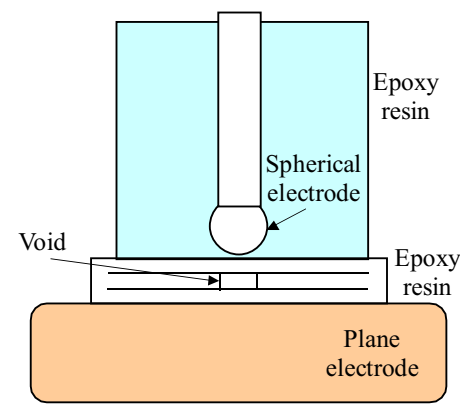

Fig. 2. Electrode arrangement with epoxy resin sample containing a void

The electrode arrangement with the sample is shown in Fig. 2. The shape of the high voltage electrode is a sphere with the diameter $5.6 \mathrm{~mm}$; to avoid the corona around the electrode when applied the voltage, the electrode is sealed by the epoxy resin, so the whole high voltage electrode is $50 \mathrm{~mm}$ in diameter and $25 \mathrm{~mm}$ in thickness. The ground electrode is plane copper electrode with the size of diameter $65 \mathrm{~mm}$ and thickness $10 \mathrm{~mm}$. The experimental samples are epoxy resin sheets with a void, $10 \mathrm{~mm}$ in

\footnotetext{
* Democritus University of Thrace, Department of Electrical and Computer Engineering, Xanthi, Greece, mdanikas@ee.duth.gr; ** Xian Jiaotong University, State Key Laboratory of Electrical Insulation and Power Equipment, Peoples Republic of China,
} 

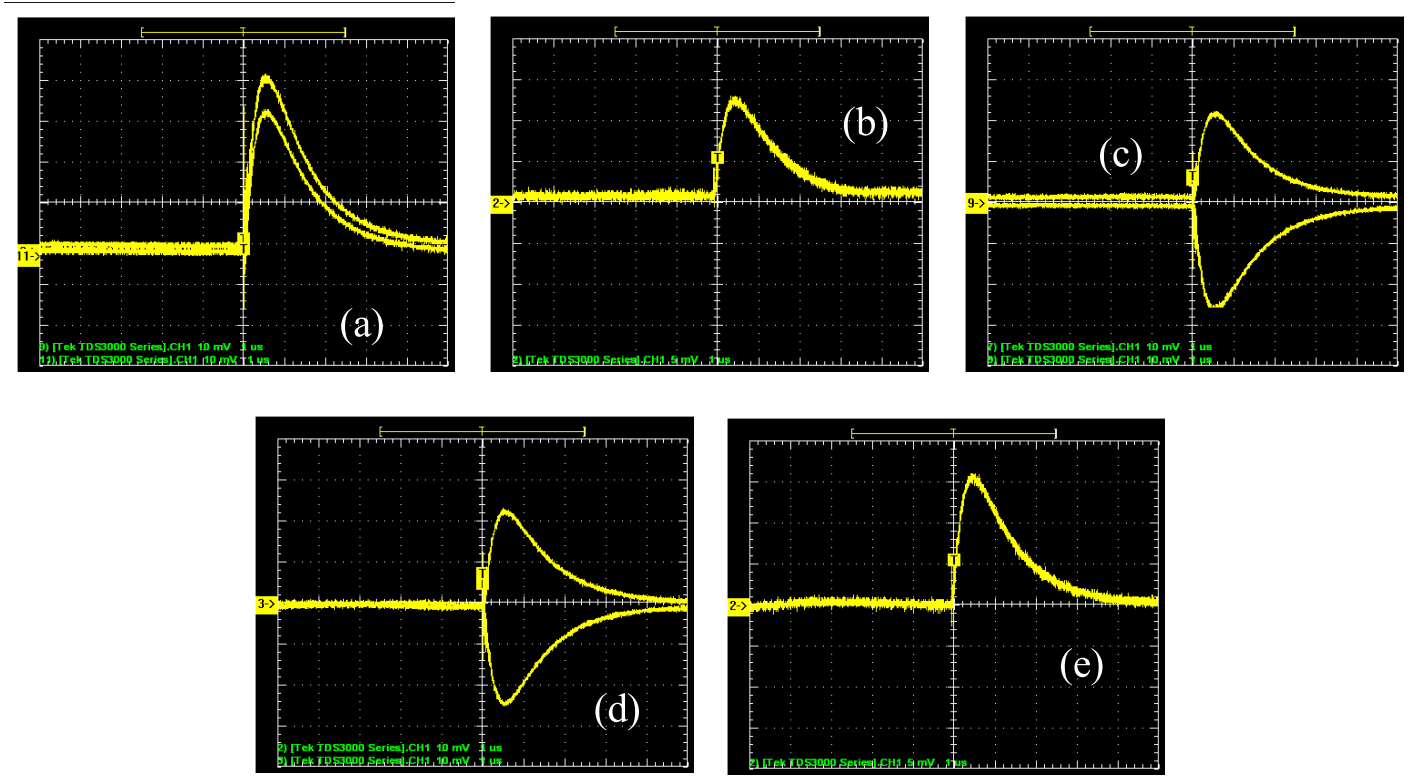

Fig. 3. aveforms of PD at inception voltage and different voltages below inception voltage; (a) $12 \mathrm{KV}$ of inception voltage, $10 \mathrm{mV} /$ div, $1 \mu \mathrm{s} /$ div; (b) $10 \mathrm{kV}$ (1 hour duration), $5 \mathrm{mV} /$ div, $1 \mu \mathrm{s} /$ div; (c) $9.5 \mathrm{kV}$ (half hour duration) $10 \mathrm{mV} /$ div, $1 \mu \mathrm{s} /$ div; (d) $9 \mathrm{kV}$ (half hour duration), $10 \mathrm{mV} / \operatorname{div}, 1 \mu \mathrm{s} / \operatorname{div}$; (e) $8.5 \mathrm{kV}$ (half hour duration), $5 \mathrm{mV} / \operatorname{div}, 1 \mu \mathrm{s} / \operatorname{div}$

diameter, sandwiched by two epoxy resin sheets. All the epoxy resin sheets are prepared in the same size, $60.0 \mathrm{~mm}$ in diameter and $2 \mathrm{~mm}$ in thickness.

\section{EXPERIMENTAL RESULTS}

Voltages, above and below the inception voltage, are applied in the experiment to compare the PD activity and its effect on the degradation of epoxy resin below inception voltage with that phenomenon induced by PD above inception voltage.

\subsection{PD waveform}

Figure 3 shows the waveforms of PD at inception voltage and different values below inception voltage.

As can be seen from Fig. 3, the duration of PD impulse occurring below inception is longer than that at inception voltage and the amplitude below inception is smaller than that at inception voltage. It can be concluded that the $\mathrm{PD}$ (or at least charging effects manifesting themselves as PD waveforms) is still in existence below the inception voltage although the duration of $\mathrm{PD}$ impulse is longer with smaller amplitude than that at inception voltage.

\subsection{Infra-Red Spectrum Analysis Results}

After the electrical tests, the powder of epoxy resin samples was collected from the surface where PD happened to conduct Infra-Red spectrum analysis. From the Infra-Red analysis (shown in Fig. 4), there seem to be no remarkable difference among the three infra-red spectrograms although some interference noises exist in the Fig. 4(a) and Fig. 4(b). If we focus on the tiny part around 1040/cm, a small difference between samples with experiment and that without experiment can be found that there is a small peak existing at about $991 / \mathrm{cm}$. That peak may give some evidence that the same effect on the epoxy resin due to $\mathrm{PD}$ at and below inception voltage worked during the experiment, but what exactly happened and what materials generated are not known yet and it will be the subsequent research.

\section{DISCUSSION}

The experiments performed indicate that below inception voltage occasional PD (or charging effects) is possible. They indicate that below inception - on some occasions - the duration of the applied voltage plays a critical role since occasional PD appear after some time of voltage application. In other words, the more the experiment endures at a voltage below inception the more probable is for PD to appear, ie the duration of charging lasts for more time and consequently it is more probable to have a charging event transformed into PD. The results are indicative but of a different nature from those published in $[1,2]$. In the present experiments, we have no direct contact of the electrode with the void. In the case of $[1,2]$, pointed electrodes were surfacing on opposite sides of an enclosed void, so to create favourable conditions for PD and/or latent PD. In the present case, something like this does not happen. One may argue that when the voltage goes below inception level, and there are still PD, it is because of the extinction voltage. In other words, one might say that we really witness extinction voltage values and not any charging effects below inception. This, however, contradicts the very definition of PD extinction voltage: 


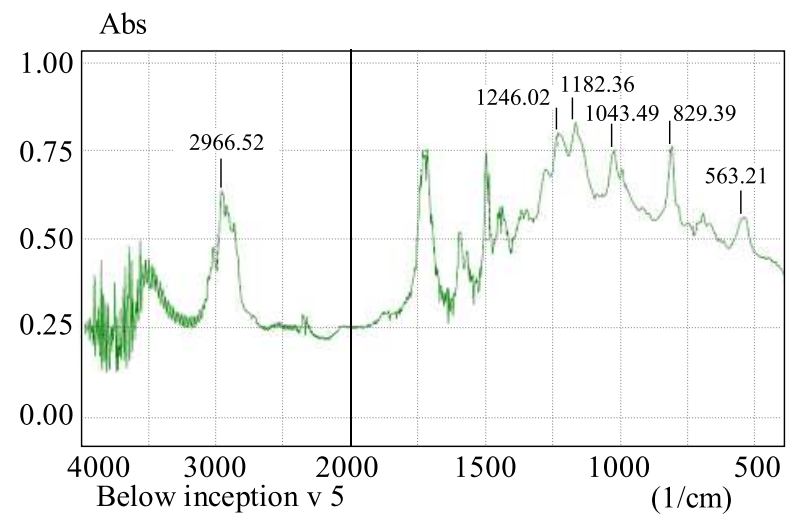

(a)
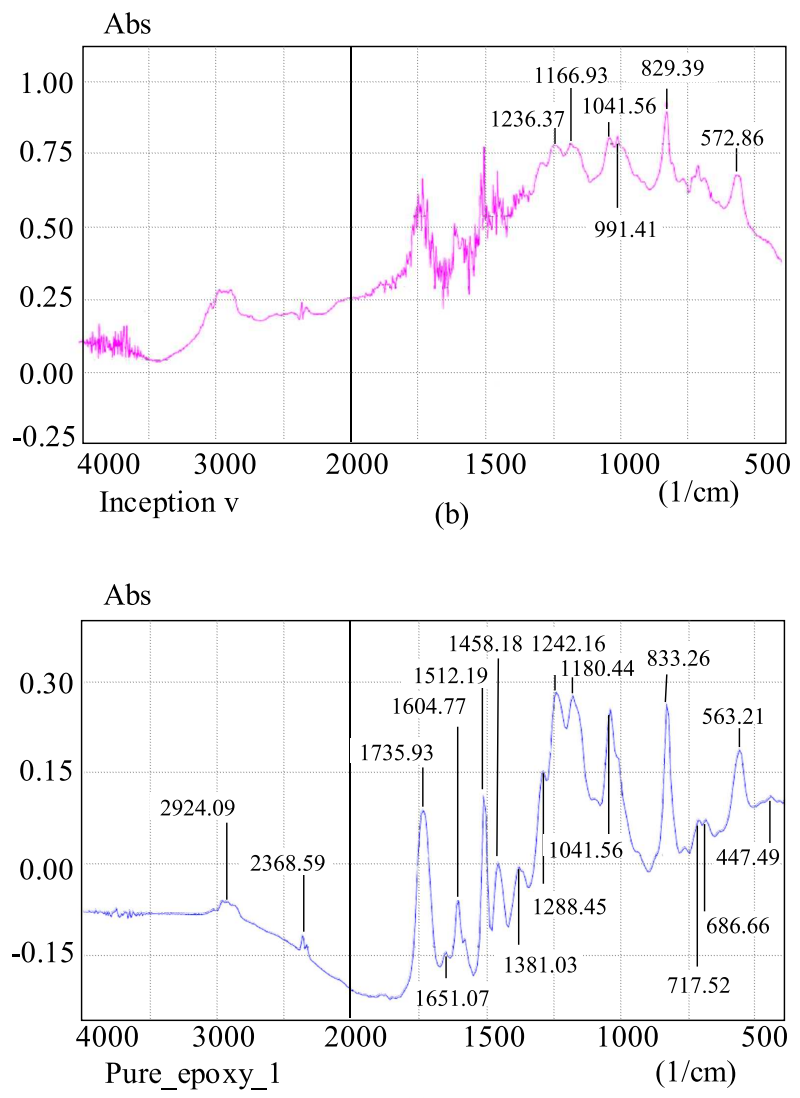

(c)

Fig. 4. Infra-Red spectrum result of epoxy resin; (a)- below inception voltage, (b) - at inception voltage, (c) - pure epoxy resin without experiment

namely, that it is the voltage at which repetitive $\mathrm{PD}$ cease to occur in the test object, as the applied voltage gradually decreases from a higher value [3]. It has to noted, however, that as we decreased the voltage, especially at the lower end of the voltages applied, there were some PD but not repetitive.

Other experiments were performed with the previous arrangement by adding three sheets of epoxy resin, each of $1.6 \mathrm{~mm}$ thickness. Experiments were performed with three epoxy resin sheets (all of them without a void) and subsequently, with three epoxy resin sheets (the middle sheet having a void of $1.81 \mathrm{~mm}$ diameter). It must be emphasized that the arrangements we used in this series of experiments were very different from the arrangement we used in the past $[1,2]$. The main difference lies into that in the present arrangement none of the electrodes touches the void. Another difference is that, whereas in $[1,2]$ the insulating material was polyethylene, ie a nonpolar polymer, in the present case the material is epoxy resin, a polar polymer. This difference may be critical regarding charging, since in a polar polymer, a charging event may more easily trap charge than a truly non-polar polymer [4]. In fact, pre-avalanche events may lead to charge trapping.

In our experiments, the voltage was slowly raised up to inception level. The slow rise gives the chance that sufficient electrons can be provided at the moment when the applied voltage reaches the target value. With the voltage applied for a long time, many PD appear and the quantity of the accumulated charge becomes sufficient not to be influenced by successive PD. Then, the PD become stable. PD characteristics are greatly influenced by the duration of the applied voltage, as was also seen in the present experiments [5].

PD depends on the detection method and/or the system which is employed, and consequently what is detected is entirely different from the detecting signals of another system. The answer to this is that, since some kind of PD and/or charging event is observed, this of course refers to a specific system of detection and that with a specific system we get specific results. Although the PD energy from a small PD (or even the energy from a charging event) is small, one may not know what sort of weak link this energy may find. Small amounts of energy may — with time - enlarge (coalesce) slight defects which in turn coalesce into larger ones. In fact, some past sudden failures of big electrical machine insulation may be due to such enlargements of previously undetected defects $[6,7]$.

Material erosion is very material dependent, this, however, goes both for "normal" PD and for charging events. As is noticed elsewhere [8], "Material erosion rates due to $\mathrm{PD}$ activity are very material dependent ... growth of electrical trees can be quite rapid during low PD levels and large PD levels can be quite harmless ... erosion [of material surface] [can be] self-perpetuating until the electrical tree bridges the insulation and complete breakdown occurs. PD accompanies the whole process". In other words, it is clearly stated that small PD may also harm the insulation. Perhaps the strongest advocate of what we are trying to present here, comes from [9], where it was emphasized that absence of detectable PD pulses need not signify absence of discharge-induced wear, but also from [10], where it was pointed out that long-term voltage degradation is due to $\mathrm{PD}$, their delivered energy and chemicals, which in turn change the insulating material.

The present experiments can be seen - and should be seen - in contradistinction to the experiments performed earlier in $[1,2]$ with polyethylene samples, and to $[11,12]$ performed in air gaps. In several cases, below the inception voltage there were PD. Are these charging 
events developing to PD? Does the epoxy resin between the spherical electrode and the epoxy sheet hinders the full development of the events below inception? That may be so, since in the previous experiments we had in fact naked electrodes touching in the first case the void, and air gaps in the second case.

The threshold level — desired minimum detectable PD is useful for rejection of noise but test results depend on the selected threshold level. This dependency makes it necessary to use different evaluation methods to define the exact inception-extinction voltage levels. This may be used as an argument against our whole approach. The answer, however, is that the experiments are performed with the available detecting equipment and with a given threshold — which should be the same for all undertaken experiments. In fact, current spikes at voltages lower than inception were observed by other researchers [13]. Such findings are in agreement some of our previously published data $[11,12,14]$. Such spikes appear besides steady components of the LCM (low current mode) which indicates to the switch - on of Fowler-Nordheim type mechanism. Trichel pulses are preceded by current spikes; the regularities are close to those taking place at higher voltages at the leading edge of a current pulse.

If what is said here, is correct, $i e$ that there is some sort of insulation degradation below the so-called inception voltage, then the whole approach to insulation ageing may be modified since there can be no certainty that insulation degrades only at/or above inception. Moreover, the lifetime models should be modified since there may be no lower limit as to the ageing voltage. A point that should be made clear in the context of the present work, is that people may object to the notion of "PD below inception voltage". This can be a ground of contention but one should keep in mind what was said above, namely that, below inception there may be charging events which may develop to PD. PD inception voltage, however, is not a constant parameter of a material and can be altered with the time. In [15], it was noted that PD inception voltage decreases during the ageing of samples. This may be due to sample ageing, void appearance, which in turn may become larger due to thermo-oxidation.

The functioning of space charges in our case cannot be underestimated. Space charges may play their role since they are the result of charge transport from the electrode to the defect (or the void). The inception voltage tends to decrease with the increase of the space charge [16]. When PD occur, space charge tends to be transported to PD. However, when PD apparently stop (or they are not detected), then there may a space charge accumulation in the sample, and this space charge eventually will be transformed (or developed) into PD [17]. If we look at the events below inception voltage from this point of view, it becomes apparent that events below inception have their own importance simply because when a sample is under an electrical field it never stops accumulating space charge.

One more aspect of the present experimental work, but a crucial one: one may say that, when we record repetitive
$\mathrm{PD}$ and then going down the voltage, we register in fact the extinction voltage and nothing else. So, one may continue, we do not register at all pre-discharge phenomena or charging events, but simply PD at extinction voltage. To this criticism we have to say that, at the lowest voltage level, first of all the PD are not repetitive but intermittent, and second - and perhaps more important — that generally speaking inception and extinction voltages do not greatly differ, as can be seen in previous papers [18]. In our case, there is a significant difference between the inception voltage and the lowest voltage at which we still observe PD. Moreover, at the lowest voltage at which we observe $\mathrm{PD}$, the latter are not repetitive but random, occasional, sporadic.

In this paper, some preliminary results with a spherical electrode - plane arrangement were given. It seems that some $\mathrm{PD}$ and/or charging phenomena (which may develop into PD) exist below the so-called inception voltage. Such preliminary results are in qualitatively agreement with previously published data. Infra-red spectrum analysis, which is a very recommended method to clarify what the material generate due to $\mathrm{PD}$, is conducted in present paper and some evidence from the analysis can support the assumption that PD occurring below inception voltage also can play some effect on degradation of epoxy resin.

\section{PROPOSALS FOR FUTURE RESEARCH}

The experiments with the same type of samples should continue with an improved sensitivity of the PD detecting circuit. Although there are indications of events occurring below the inception level, another experimental arrangement, with the spherical electrode surface touching the surface of the void - much in line with the experiments reported in $[1,2]$ — should be tried out. Things may occur more easily if we have naked electrode touching the surface of the epoxy resin samples, simply because there may be a better and easier electron emission from the electrode. Such an arrangement may also relate much closer to the experimental work reported in $[1,2]$. Chemical analysis of the void surfaces both at inception and well below inception voltage, might also give a clue regarding our effort. Chemical analysis should be tried also with the new arrangement proposed here. The nature of deterioration byproducts should be investigated and thoroughly studied. Although there are indications that the byproducts above and below inception are very similar (ie that PD above inception cause failures similar to charging events below inception), more light should be shed on this $[1,19]$.

Even though the above proposals can be realized, the conclusions will not be final as to the existence of charging effects below the inception voltage. More work should be done including in our approach not only conventional 
polymers, but also polymers with nanofillers. Nanocomposite polymers consist at the moment a very promising field of research and possible applications, and they should be tried in experiments at and/or below the inception voltage. Given the generally better performance of nanocomposite polymers wrt to the conventional polymers, the authors of this paper are convinced that useful information will come out from such experiments.

Last but not least, and under the condition that the above mentioned research will bring some new knowledge, the academic and industrial community should see again the definitions of classical terms such as "inception voltage" under a new light. Does "inception voltage" imply really the critical voltage below which no degradation takes place? In that respect, the above proposed research may somehow change long-time perceptions [20-22].

\section{CONCLUSIONS}

In this paper it was shown that there are charging phenomena below the inception voltage with the epoxy resin samples tested. This goes contrary to the conventional wisdom which says that below inception, no important events take place. Ionizing events or charging phenomena (or whatever name or definition one wants to give to these events) are a reality, as far as the experiments reported here. It remains to be seen whether such events may cause deterioration of the electrical insulation, as some researchers pointed out before.

\section{REFERENCES}

[1] BRUning, A. M. KASTURE,-D. G.-CAMPBELL, F. G. C.-TURNER, N. H. : Effect of Cavity Sub-Corona Current on Polymer Insulation Life, IEEE Trans. Electr. Insul. 26 (1991), 826-836.

[2] BRUNing, A. M.-DANIKAS, M. G.: Observations on Discharges Above and Below CIV in Polymer Insulation, Ann. Rep. CEIDP, October 1991, Knoxville, Tennessee, USA, 1991, pp. 638-647.

[3] British Standard BS EN 60270:2001, IEC 60270:2000, High-Voltage Test Techniques - Partial Discharge Measurements.

[4] BeRnstein, B. S.: Personal Communication, July 2010.

[5] HAYAKAWA, N.-OKOSU, T.-NISHIZAWA, K.-KOJIMA, H.-ENDO, F.-YOSHIDA, M.-UCHIDA, K.-OKUBO, H.: Dependence of Partial Discharge Characteristics at Spacer Surface Particle Size in SF6 Gas-Insulated System, 2008 Int. Conf. Condition Monitoring and Diagnosis, Beijing, China, April 21-24, 2008.

[6] BRUNing, A. M.: Design of Electrical Insulation Systems, PhD Dissertation, University of Missouri, Comumbia, USA, May 1984.

[7] JONSCHER, A. K.-LACOSTE, R. : On a Cumulative Model of Dielectric Breakdown in Solids, IEEE Trans. Electr. Insul. 19 (1984), 567-577.

[8] ORTON, H. : Partial Discharge Testing of in-situ Power Cable Accessories - an Overview, Electric Energy

http://www.electricenergyonline.com/ ?page $=$ show_article $\&$ mag $=6 \&$ article $=44$.

[9] HUDON, C.-BARTNIKAS, R.-WERTHEIMER, M. : Chemical and Physical Degradation Effects on Epoxy Surfaces Exposed to Partial Discharges, Proc. Int. Conf. Prop. Appl. Diel. Mater., 1994, pp. 811-814.
[10] REHDER, R. H.-MULHALL, V. R.-MOORE, V. A.-McLAREN, D. G.: All Stator Windings Are Not Created Equal, ICPADM 2 (1988), 42-446.

11] DANIKAS, M. G.: On the Discharge Phenomena Below Inception Voltage: Further Experimental Results with Air Gaps, J. Electr. Eng. 53 No. 1-2 (2002), 58-60.

12] DANIKAS, M. G.-PITSA, D.: Detection and Registration of Partial Discharge Events Below the sdo-called Inception Voltage: The Case of Small Air Gaps, J. Electr. Eng. 59 No. 3 (2008), 160-164.

13] REPAN, V.-LAAN, M.-PARIS, P.-AARIK, J.-SAMMELSELG, V.: Negative Coronas: Low Current Mode-Pulse Mode Transition, Czechoslovak J. Phys. 49 No. 2 (1999), 217-224.

14] DANIKAS, M. G.: Detection and Recording of Partial Discharges below the Inception Voltage with a Point-Plane Arrangement in Air: Experimental Data and Definitions, J. Electr. Eng. 61 No. 3 (2010), 177-182.

[15] SCHLupP, P. BOUCheR, V. RAIN, P. PETIT, A.: Partial Discharge Measurements on Glass-Mica-Epoxy Samples for Electrical Insulation during Accelerated Thermo-Oxidative Aging, Int. Electr. Insul. Conf., Birmingham, UK, 2009.

[16] SEGHIER, T.-MAHI, D. : Investigation into Partial Discharge Dependence in Air Gaps Between High Density Polyethylene Tapes, Acta Electrotehnica 49 No. 1 (2008), 3-13.

17] DISSADO, L.: Personal Communication, July 2010.

18] GHOSH, S.-KISHORE, N. K. : Modelling of Partial Discharge Inception and Extinction Voltages of Sheet Samples of Solid Insulating Materials Using an Artificial Neural Network, IEE Proc.-Sci. Meas. Technol. 149 No. 2 (2002), 73-78.

[19] TURNER, N. H.-CAMPBELL, F. J.-BRUNING, A. M.KASTURE, D. G. : Surface Chemical Changes of Polymer Cavities with Currents above and below Corona Inception Voltage, Ann. Rep. Conf. Electr. Insul. Diel. Phen. (CEIDP), 18-21 October, 1992, Victoria, B.C., Canada, pp. 687-693.

[20] KELEN, A. : Studies on Partial Discharges on Solid Dielectrics: A Contribution to the Discharge Resistance Testing of Insulating Materials, Acta Polytechnica Scandinavica, Electrical Engineering Series (1967), p.138.

[21] TANAKA, T.-GREENWOOD, A.: Advanced Power Cable Technology, Vol. I (Basic Concepts and Testing), CRC Press Inc., Florida, USA, 1983.

22] KUFFEL, E.-ZAENGL, W. S.-KUFFEL, J.: High Voltage Engineering: Fundamentals, 2nd edition, Newnes, Oxford, England, 2000.

Received 21 February 2011

Michael G. DANIKAS is Professor with the Department of Electrical and Computer Engineering, Democritus University of Thrace (DUTh). He was with Eindhoven University of Technology, The Netherlands, and with ABB, BadenDaettwil, Switzerland, before he joined DUTh. His research interests include breakdown in transformer oil, polymeric insulation breakdown processes, vacuum breakdown, partial discharge activity at inception voltages, simulation of electrical trees in polymeric materials and nanocomposites and partial discharges in rotating machine insulation.

Xu ZHAO was born in 1982. He received the BS in electrical engineering from Southeast University, China in 2006. Since 2009, he is a PhD student in Xi'an Jiaotong University.

Yong-Hong CHENG was born in Anhui, China in 1965. He received the MS and $\mathrm{PhD}$ degrees in electrical engineering from Xi'an Jiaotong University, China in 1991 and 1999, respectively. Since 2001, he is a professor of Xi'an Jiaotong University. 